\title{
Motivating learners through intercultural communicative language teaching (iCLT)
}

\author{
Dr. Jonathan Newton \\ Victoria University of Wellington
}

Reference: Newton, J. (2014). Motivating learners through intercultural communicative language teaching (iCLT). JANTA News, 86: 14-19 (JapanAustralia-New Zealand Teachers Association).

As a large organization focused exclusively on language teaching for speakers of other languages, Language Education Expo annually hosts many language educators from across Japan and around the world. Educators at all levels attend to find a productive exchange of ideas and information and to feel the embrace of a dynamic professional community. Natsue Nakayama (JANTA, Kyoai Gakuen University associate professor) introduced Dr. Jonathan Newton from Victoria University of Wellington at the Language Education Expo 2014. He held a workshop on motivating learners through intercultural communicative language teaching (iCLT).

My talk to you today is about teaching language interculturally, that is, teaching in a way that fosters opportunities for learners to develop a deeper understanding of culture and culture-in-language in their own lives and in the lives of others. It focuses on the awareness and skills necessary to navigate cross-cultural encounters and experiences, and to participate successfully in an increasingly complex multicultural world.

To begin this talk it is perhaps worth clarifying what we mean by culture because this term is not well understood. What is culture? Here is a traditional definition: 'the sum total ways of living built up by a group of human being and transmitted for one generation to another'. But it's not so simple, of course. Culture is variable, contested, ever-changing and incomplete. It's dynamic, it shifts around, and it's hard to pin down. Here is an alternative definition: 'Culture is a daily lived phenomenon, that is, patterned and shared, under a current of values and beliefs that guides behavior'. I think this captures the dynamic illusory nature of culture. 


\section{What is culture?}

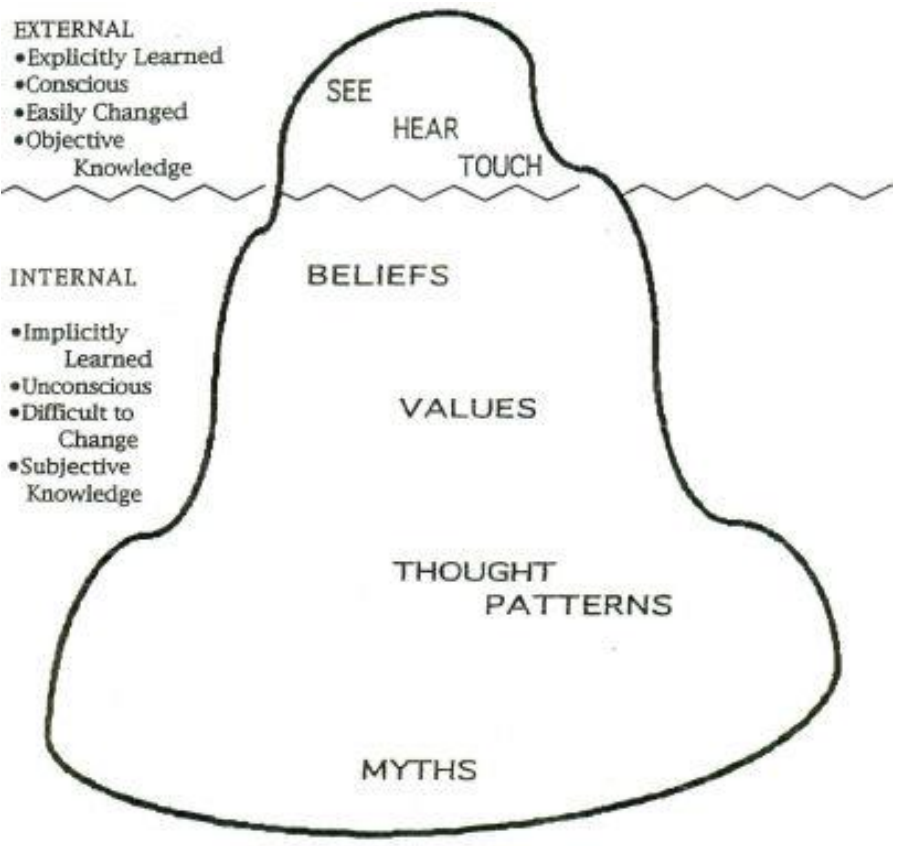

You may be familiar with the notion of the cultural iceberg. What we see, hear, and touch, for example paintings, art work, festivals and other traditions represent a very visible and yet really quite small part of culture the small tip of the iceberg that is above water. But the vast majority of cultural knowledge is less visible and is largely implicit. It includes beliefs and values and ways of seeing the world. In fact much of this cultural material only becomes visible to us when we are placed in culturally unfamiliar surroundings and see our 'cultural' selves as if for the first time, as if through the eyes of a stranger. (http://home.snu.edu/ hculbert/iceberg.htm).

\section{Approaches to teaching culture}

The iCLT approach to teaching and learning culture which I describe below stands in marked contrast to more traditional approaches. These often focus on 'big ' $\mathrm{C}$ ' culture' which teaches about the static, observable parts of the cultural iceberg - the literature, visible arts, national foods, etc. While this is a legitimate part of teaching culture, it has limits for the purpose of developing intercultural competence. First, it only covers a very small part of culture as we saw with the iceberg. Second it too often leads to stereotyping and essentializing culture. You see this in statements like "Germans are very punctual", Italians are very passionate, or "Australians are very laid back". In such statements the whole culture is reduced to some simplistic essence which hides diversity and dynamism. It implies that we are cultural products rather than cultural agents who in every action we take construct and reconstruct culture.

\section{The background to iCLT}

iCLT emerged out of a major overhaul of the school curriculum for the compulsory education sector (Years 1 to 13 of schooling) in New Zealand culminating in the release of The New Zealand Curriculum in 2007 (http://nzcurriculum.tki.org.nz/). This is a very 
interesting document for anyone interested in curriculum design. But it is particularly interesting from our perspective as language teachers for the way it explicitly and unambiguously presents a strongly intercultural agenda for education in New Zealand. Here are some of the key competencies identified in that curriculum document:

- Participating in local, national and global communities;

-Students knowing who they are, where they come from and where they fit in;

- Relating to others - interacting effectively with a diverse range of people in a variety of contexts; Seeing the world from new perspectives;

-Valuing diversity and respecting others;

- Learning about their own values and those of other peoples and cultures;

-Exploring with empathy, the values of others. (New Zealand Curriculum, 2007)

Note that these statements present intended outcomes for the whole education system and not just learning languages. However, any language teacher will be able to identify very quickly the potential of language learning for realizing these kinds of objectives. Likewise, The Ministry of Education also wanted to adopt a principled approach to intercultural language learning in schools as part of the new curriculum. For this purpose I was part of a team at Victoria University of Wellington commissioned to carry out research in this area and to review the literature, to interview teachers and students, observe at classes, and come up with a framework that might drive a more inter-culturally informed approach to language teaching in New Zealand schools. That research resulted in a report to the ministry (Newton et al., 2010) which is available via the link provided below. A key part of that report is the following six principles for iCLT.

\section{The Six principles for intercultural communicative language teaching (iCLT):}

In iCLT the teacher:

1) integrates language and culture from the beginning;

2) engages learners in genuine social interaction;

3) encourages and develops an exploratory and reflective approach to culture and culture-in-language;

4) fosters explicit comparisons and connections between languages and cultures;

5) acknowledges and responds appropriately to diverse learners and learning contexts;

6) emphasizes intercultural communicative competence rather than native-speaker competence.

The first principle makes the point that teachers should encourage learners to think interculturally from the very first lesson: Consider for example how much rich cultural content is embedded in the different ways in which we greet each other in different parts 
of the world. How does a student typically address the teacher in Japan? How do they do so in another country? I'm sure there will be interesting differences as well as similarities. Exploring these connections is a form of teaching interculturally.

The second principle emphasizes the point that culture emerges when we put language to use since communication is shaped by cultural values. As Claire Kramsch (1993) so elegantly puts it, 'Every time we speak we perform a cultural act'.

The third principle emphasizes experiential, constructivist learning processes which are needed if students are to develop their intercultural competence in the language classroom. Rather than teachers' telling students about culture, their role is one of encouraging students to discover, to observe, to notice, to pay attention to culture; in short to develop sensitivity to culture in their lives and interactions.

This leads us to the fourth principle. By making comparisons and connections between experiences of languages, cultures and communication, learners start to make sense of cultural differences. Comparisons though, are not simply between one stereotype and another, i.e., "Japanese do it this way," or "We do it that way." Likewise, we should be aiming to move away from comparisons between national groups. In contrast, the kind of comparisons to encourage in intercultural learning are those that based on experience and observation and that involve guided reflection. This reflective process, guided by the teacher, is essential if we are to avoid the danger of comparisons simply reinforcing stereotypes! When we make comparisons in our everyday life we too often look outwards at the 'other' and judge him/her against our own cultural frame of reference. In iCLT this process is reversed. Intercultural comparison typically starts by encouraging learners to reflect on themselves and their own ways of being, doing and thinking. They are then encouraged to consider how they might be viewed by the other. Only then does the learner turn attention outwards and consider other views and experiences of the cultural 'other'. The aim of this process is to develop a deep reflectivity and sensitivity to how $I$ and my behavior might be perceived and to use this as the basis for becoming aware of the underlying process by which we construct our view of the world. To foster this kind of intercultural learning the teacher will need to provide a metalanguage involving terms such as culture, invisible culture, same, different, self, identity, stereotypes, prejudice, and so on.

Of course we can't avoid stereotypes, and indeed they are a useful starting point for critical reflection so long as these stereotypes are problematized. Indeed I think that gaining insights into stereotyping and the stereotypes one holds is a critical transformative process that can lead to deep reflexivity.

The fifth principle encourages teachers to make the most of diversity in the 
classroom, school and community by recognizing and connecting to learners' home knowledge, languages and practices, and by making links beyond the classroom to English in the community. This is a particularly important principle in New Zealand because our classes are so multiethnic. In my daughter's school, for example, there are 17 different ethnic groups. So you can see the potential for using school diversity to foster interculturality in this context!

The final principle emphasizes the importance of teachers and curricula recognizing intercultural learning achievements alongside linguistic and communicative achievements. This principle is a deliberate attempt to shift attention away from some perfectly, albeit illusory, standard of native speaker competence.

In a nutshell, teachers who adopt these principles will emphasize the dynamic lived experience of culture, encourage reflective dialogue, and guide students as they interpret their experience.

To see these principles in action, let us look at the steps a teacher might take to apply the principles to the design of a classroom lesson. In this case, the lesson is for teachers of the Japanese language in New Zealand schools, but an English teacher in Japan can easily apply the design principles in this lesson to teaching English. The lesson topic here is the food typically sold at a school canteen, colloquially known in New Zealand as a 'Tuck shop'.

\section{Lesson planning from an iCLT perspective}

Intercultural learning relies on opportunities for learners to experience intercultural communication. Unfortunately, many language learning activities involve learners in manipulating or practicing language in a communicative vacuum or where language use is only superficially communicative. One way to address this problem is to turn activities into communicative events. In a communicative event, learners communicate valued meanings or information to someone for a real or imagined purpose. As soon as we engage learners in not just activities, but in communicative events, we are opening up opportunities for intercultural language learning. This is because people involved in a communication event have to make choices about language and content that are deeply influenced by their cultural background. In the remainder of this article we look at how a suggested activity from the Japanese Curriculum Guidelines is reshaped into a communicative event which in turn is used as a tool for intercultural learning.

\section{Step 1: Choose the activity}


As we see below, lesson planning for intercultural language learning starts with curriculum guidelines - choosing an objective, a communicative setting, and then one or more of the suggested activities.

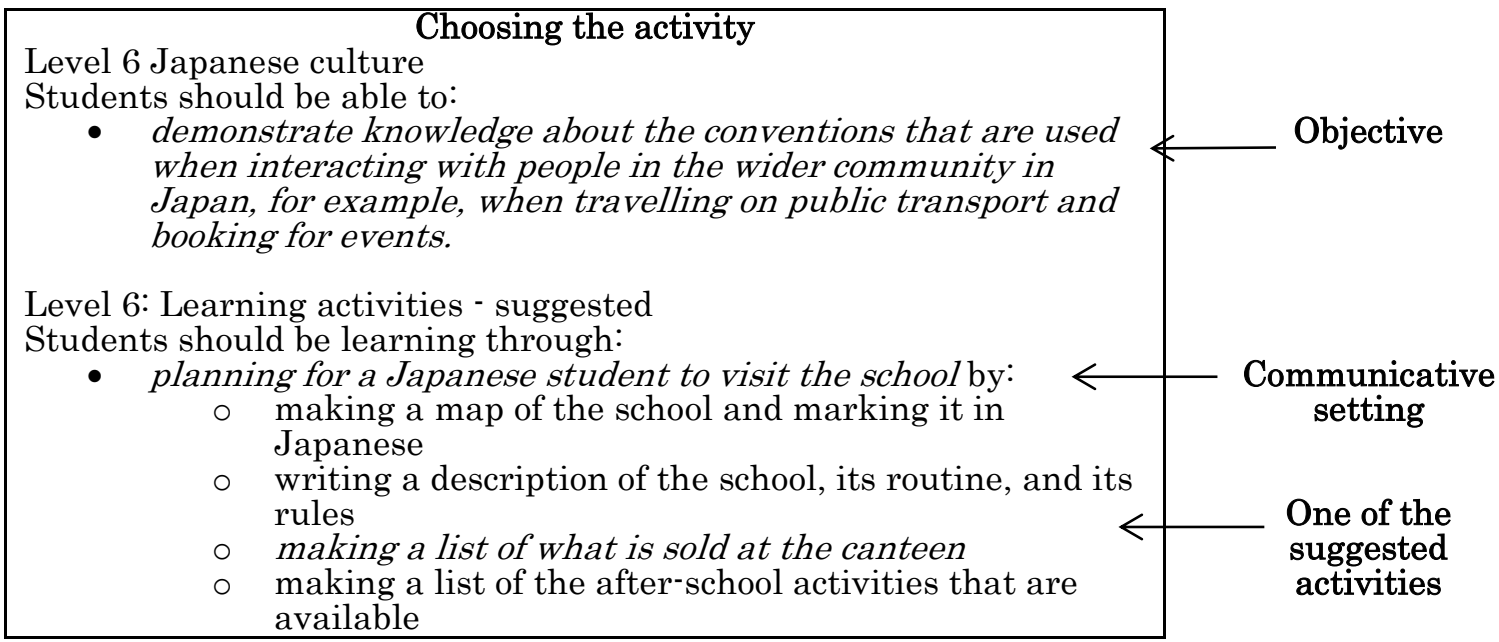

The activity which we focus on (making a list of what is sold at the [school] canteen) is from Level 6 of the Curriculum Guidelines for Japanese. The presence of a stated communicative setting in this particular set of activities provides a useful starting point for making the activities listed here into richly communicative events.

\section{Step 2: Create a communicative event from the activity}

The next step is to think about what kind of communicative event would suit the activity. I have chosen the event of a letter, written by a group of students working on this activity, and written to a student (or group of students) in Japan. In the letter, the group not only list the foods sold in the canteen, but also inform their Japanese peers of some other interesting aspects of food culture at school. (I see value in having different groups in the class working on the various activities, and then reporting to the class and/or sharing and comparing outcomes with each other.)

\section{Step 3: Identify opportunities for intercultural learning}

Next, the teacher thinks about the opportunities for intercultural communication and learning that they would expect to see in the group's work. The following list of questions provide prompts for encouraging intercultural reflection and enquiry:

a) What might Japanese students find novel in the tuck-shop menu?

b) How could we add to the menu to make it more inclusive for Japanese students?

c) If the menu was more inclusive, what would you buy that might encourage the shop 
to stock Japanese food?

d) Should the menu be inclusive, or should Japanese students just 'fit in'?

e) How do Japanese people of your age usually begin and close letters to one another?

f) What is similar and what is different in the various styles of letter writing between people of different cultures?

Exploring such questions becomes part of the intercultural learning experience afforded by involvement in the communicative event. These kinds of questions can be used to guide the learners' engagement in the communicative event, as well as to generate further discussion before and after the letter has been written. Some of the considerations generated by answering these questions are reflected in the letter below. I have identified three signs that the letter reflects intercultural learning. The signs appear on the right of the sample letter (which would be written in Japanese).

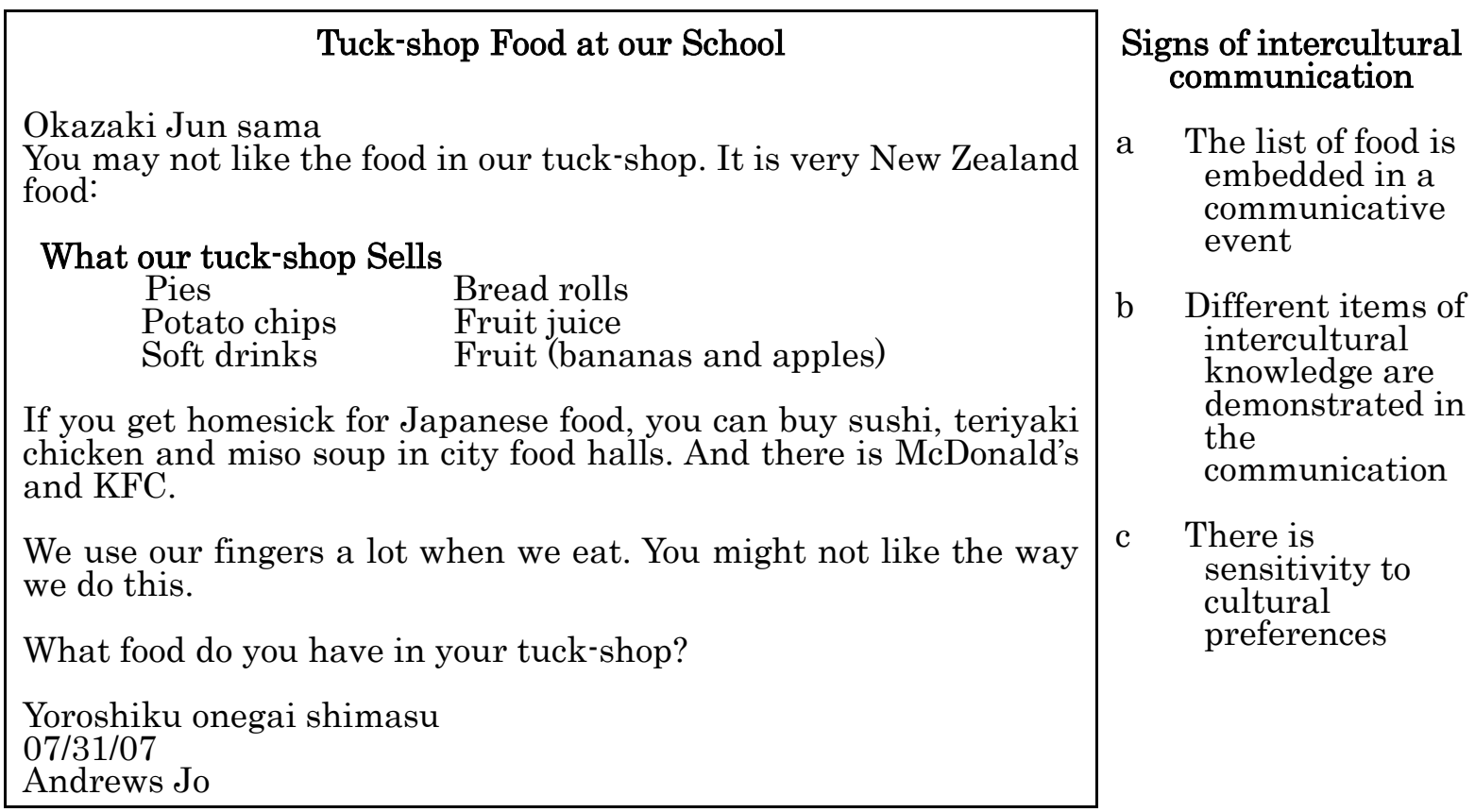

Notice how the learning opportunities in the lesson are consistent with iCLT. For example, in making a list of what is sold at the canteen, learners will be:

a) exploring cultural differences in letter writing and snack-food preferences;

b) paying attention to cultural expectations in the way information is communicated in letters;

c) thinking critically about cultural stereotypes.

\section{Summary}


Let me conclude with some general points about teaching interculturally. First, iCLT is not intended to be a new method or approach. It is a way of fostering intercultural learning opportunities through existing lessons and topics. Even traditional cultural knowledge can be approached interculturally, although obviously, it is when learners have opportunities to interact in the language that intercultural opportunities flourish. It follows then that an intercultural stance in language teaching can take many forms. It influences how you teach (e.g. encouraging learners to explore their intercultural experiences), what you teach (e.g. a focus on lived experience and critical reflection on stereotypes), and what learning outcomes are valued (e.g. showing intercultural awareness as well as grammatical accuracy). Finally, intercultural teaching relies on an intercultural teacher who models and indeed embodies intercultural values such as curiosity and openness and a willingness to learn alongside the learner.

\section{Acknowledgement}

This article is based on material included in a report on intercultural language learning commissioned by the New Zealand Ministry of Education and published in 2010. The report is available via the following link:

http://www.educationcounts.govt.nz/publications/curriculum/76637/introduction 